\title{
TRADISI MENDIRIKAN IMAH GEDE DAN RUMAH WARGA DI KASEPUHAN SINAR RESMI KABUPATEN SUKABUMI
}

\author{
THE TRADITION OF BUILD IMAH GEDE AND CITIZEN HOUSE \\ IN KASEPUHAN SINAR RESMI, SUKABUMI REGENCY
}

\author{
Nandang Rusnandar \\ Balai Pelestarian Nilai Budaya Bandung \\ Jln. Cinambo 136 Ujungberung-Bandung \\ e-mail: nd_roes@yahoo.co.id

\begin{abstract}
Abstrak
Salah satu komunitas adat Kasepuhan Sinar Resmi yang berada di Kabupaten Sukabumi, banyak melakukan ritual. Dan salah satu ritus yang dilakukannya adalah ritus dalam mendirikan rumah dan rumah adat. Tradisi ritus ini dilakukan dari sejak awal pembangunan hingga selesai mendirikan rumah, sehingga pembangunan dapat terselesaikan dengan baik dan keluarga yang akan menghuni rumah tersebut dapat hidup dengan selamat. Pembangunan sebuah rumah tak lepas dari ritus yang secara adat selalu dipatuhi dan dilaksanakan dengan benar, hal tersebut sangat erat kaitannya dengan sistem kepercayaan yang mereka anut. Hal itu dilaksanakan, karena mereka takut akan melanggar pamali. Demikian pula rumah dan pola perkampungan yang ada di Kasepuhan Sinar Resmi erat hubungannya dengan alam sekitar, sehingga rumah dapat dianalogikan sebagai 'mikro kosmos' atau bumi 'makro-kosmos' yang berarti alam semesta. Penelitian ini bersifat deskriptif dengan pendekatan kualitatif. Hasil penelitian menunjukkan bahwa ritus tradisi mendirikan rumah dan rumah adat merupakan kearifan tradisional yang mampu memberikan keharmonisan antara manusia dengan alamnya dan keharmonisan kehidupan sosialnya.
\end{abstract}

Kata kunci: Kearifan, tradisi, rumah dan rumah adat.

\begin{abstract}
One of the indigenous communities of Kasepuhan Sinar Resmi are in Sukabumi performed many ritual. One rite is a rite in setting up homes and custom homes. This tradition carried on since the beginning of construction till finished, so the building can be resolved properly, and the families who will inhabit the house can live safely. Build a house could not be separated from the customary rite which implemented properly, it is very closely related to the belief system that they possessed. They do that thing because they fear would violate the taboos (pamali). Similarly, the house and the existing settlement pattern in the Kasepuhan Sinar Resmi closely related to the environment, so the house can be analogized as 'micro cosmos' or the earth 'macro-cosmos' which means as a universe. This research is descriptive with qualitative approach. The results showed that the rite tradition and building a custom house is a traditional wisdom that is able to provide harmony between human and nature and the harmony of social life.
\end{abstract}

Keywords: wisdom, tradition, house and custom house.

\section{A. PEN DAHULUAN} pengetahuan budaya khususnya tentang tradisi mendirikan terfokus pada
bangunan.Komunitas yang diteliti adalah komunitas kecil yang hidup di sebuah kampung adat bernama Kasepuhan Sinar Resmi di Kabupaten Sukabumi. Adat 
istiadat masyarakat Kasepuhan Sinar Resmi dapat dilihat sebagai berikut:

1. Mengenal adat tatali paranti karuhun secara turun temurun.

2. Pamali, tabu, pantangan, kabendon.

3. Tradisi ritual (ritus-ritus); upacara adat mendirikan kampung.

4. Anjuran dan larangan.

5. Upacara adat perkawinan, sunatan, saweran.

6. Upacara dalam pertanian (masa bercocok tanam)

7. Sistem kepemimpinan secara dinasti.

8. Pimpinan adat; sesepuh, kolot.

9. Upacara dalam mendirikan rumah. Pengalaman manusia untuk menetap pada sebidang lahan merupakan pilihan dan telah membangkitkan pemahamannya atas tempat berpijak yang mampu mendukung kelangsungan hidupnya.Tjahjono, dalam esainya "Membangun Diri dan Mendiri Bangun dalam Pembuatan Rumah Adat di Desa Wae Rebo: Suatu Pengantar" (2010:11) menyatakan bahwa pemaknaan akan lahan senantiasa ditandai dengan menyucikan terlebih dahulu untuk memohon izin kepada Yang Maha Kuasa dan karuhun agar tempat berpijak terberkahi. Dengan demikian berhuni di situ akan mencapai ketentraman batin dan tindakan membangun mendapat persetujuan, lalu dari situ dapat membangun kesepakatan bersama untuk memertahankan tempat berpijak. Le Corbusier, menyebutnya sebagai tindakan akibat pemikiran primitif. Ia menyatakan bahwa gagasan primitif merupakan pikiran awal yaitu perpaduan antara akal dan rasa yang menghasilkan penghayatan terhadap ruang bergiat yang mampu mendorong manusia bertindak memenuhi hasratnya untuk berada di atas bumi ini. Antar, (2010:12). Menyatakan bahwa: "Melalui tanda, diri ternyatakan". Diri dengan demikian terejawantahkan dengan bangun, yakni dengan suatu hasil karya. Karya bangun ini disebut karya arsitektur yang lahir dari segenap jiwa saat tanda pertama dilahirkan, bukan dibuat apalagi dibuat-buat. Membangun, meminjam istilah arsitek kondang Robi Soelarto (dalam Antar, 2010:12), adalah dharma. Dharma adalah kewajiban, bukan keharusan. Dharma tumbuh dari dalam diri, sanubari, tanpa harus melalui pertimbangan panjang tetapi langsung melakukan.

Pemahaman akan kebutuhan bersahabat dengan alam itu, perlu diturunkan atau diwariskan kepada generasi-generasi berikutnya sejauh pengalaman membuahkan hasil. Dengan demikian terbangun suatu tradisi yang bertumpu pada ritus.Tjahjono, mengatakan bahwa selama menjalankan kehidupan dalam keterikatan tradisi itu membawa berkah, maka makna langsung bersemi dan tradisi berlanjut. Jika suatu saat ritus menjadi kewajiban yang menyentuh hanya permukaan karena telah ada tantangan baru, maka tradisi kehilangan makna dan kehadirannya akan menimbulkan pertanyaan.

Untuk mengungkapkan kepercayaan akan makna hidup, manusia memakai lambang atau tanda. Melalui lambang, sesuatu hal yang awalnya bersifat materi menjadi hal yang bersifat rohani. Alam perlambangan memperlihatkan dan mengisyaratkan suatu kenyataan yang mengatasi alam empiris/fenomenal. Demikian pula tanda-tanda berlambang merupakan unsur mutlak dalam sikap manusia terhadap hakikat terakhir hidupnya. (Subagya, 1981:116) Berkaitan dengan hal itu, ritus atau upacara adalah kelakuan simbolis yang mengkonsolidasi atau memulihkan tata alam dan menempatkan manusia serta pembuatannya dalam tata tersebut. Dalam ritus dipergunakan kata-kata atau doa, dan gerak tangan atau badan sebagai simbol yang bermakna mengokohkan tata rencana alam raya yang diharapkan akan memberikan keselamatan bagi umat manusia.

Masyarakat Kampung Sinar Resmi, memberikan gambaran kepada kita model kedekatan mereka dengan lingkungalam dan lingkung-bangun. Tataolah 
membangun rumah baik rumah sendiri maupun rumah adat yang melibatkan segenap masyarakat Kampung Sinar Resmi merupakan suguhan ritus yang tak meluntur, karena tradisi telah berlanjut.

\section{A. METODE PENELITIAN}

Penelitian mengenai Tradisi Mendirikan Rumah di Kampung Kasepuhan Sinar Resmi ini dilakukan secara deskriptif analitis, yaitu penelitian yang bertujuan untuk memberikan gambaran secara sistematis, faktual, dan akurat mengenai fakta-fakta sebagai bahan untuk menganalisis permasalahan secara komprehensif. Metode pengumpulan data dalam penelitian lapangan dimaksudkan sebagai pelengkap, yaitu untuk mendukung dan menganalisis. Teknis pengumpulan informasi dilakukan dengan wawancara mendalam (indepth interview) terhadap tokoh lokal sebagai pemangku adat atas kebudayaan lokal di Wilayah Kasepuhan Sinar Resmi dan tokoh-tokoh lainnya yang berkaitan dengan kepakaran dalam hal ritus di kampung tersebut. Metode analisis data dilakukan dengan pendekatan kualitatif, sehingga setiap informasi dan data yang diperoleh atau berhasil dihimpun dapat dideskripsikan yang kemudian dianalisis. Dengan metode ini, diharapkan terkumpul data yang berkaitan dengan deskripsi nilainilai budaya yang mengatur kehidupan masyarakat pendukungnya yang tercermin dalam kelakuan, tata kelakuan, dan hasil kelakuan pada warga pendukungnya.

\section{C.HASIL DAN BAHASAN \\ 1. Mendirikan Imah Gede ( R umah A dat)}

Segala bentuk yang berurusan dengan Imah Gede, merupakan kegiatan yang bersifat komunal. Artinya bahwa Imah Gede merupakan kepemilikan bersama seluruh warga Kasepuhan Sinar Resmi. Ketika Imah Gede akan dilakukan perbaikan dan perombakan, maka seluruh warga akan terlibat di dalamnya. Begitu pula ketika Imah Gede akan direnovasi, seluruh warga terlibat dari semua kegiatan untuk menentukan semua tahapan pekerjaannya.

Tata cara membangun Imah Gede, secara garis besar berbeda dengan tata cara membangun rumah tempat tinggal pada umumnya. Imah Gede merupakan rumah yang dijadikan tempat tinggal Ketua Adat yang sekaligus menjadi tempat bermusyawarah seluruh warga Kasepuhan Sinar Resmi. Imah Gede dianggap menjadi rumah yang suci dan agung, maka dalam pembangunannya harus memerhatikan segala bentuk tata cara yang telah ditentukan secara adat. Imah Gede merupakan rumah bersama seluruh warga kasepuhan, dengan demikian segala bentuk perubahan yang terjadi pada bangunan ini harus diketahui oleh warganya, begitu pula dalam pengerjaan pembangunan dilakukan secara bergotong royong oleh seluruh warga kasepuhan.

Pada waktu Imah Gede akan dibangun kembali oleh Abah Asep, maka seluruh warga diajak bermusyawarah, untuk menentukan jumlah dana yang diperlukan, waktu, dan pekerja. Untuk mendirikan Imah Gede ini memiliki beberapa tahapan yang harus dilaluinya, yaitu sama dengan tata cara membangun rumah pada umumnya. Diawali dengan mengadakan musyawarah dan diakhiri dengan ngabenteng.

Musyawarah dilakukan dengan cara berkumpul di rumah Abah (Sesepuh Kampung Sinar Resmi), Para kokolot lembur dan semua tukang bas datang untuk berembuk menentukan hari baik untuk memulai pelaksanaan pekerjaan dilanjutkan dengan rembukan biaya yang akan dikeluarkan dalam memenuhi kebutuhan material dan bahan-bahan bangunan. Tukang Bas merencanakan seluruh jumlah kebutuhan bahan-bahan material, biaya dan bentuk atau gaya rumah yang akan dibangun kemudian. Para kokolot lembur berembuk untuk menentukan besaran biaya yang akan ditanggung oleh setiap warga sebagai bentuk iuran bersama, di samping itu para kokolot lembur akan menentukan hari baik 
waktu pelaksanaan. Semua elemen masyarakat ikut bersama-sama membangun Imah Gede.

"Ari ngadamel bumi nu abah mah musawarah kempelan sadayana heula tiap sesepuh nu nganut kasepuhan $\mathrm{ka}$ abah asep, ieu abah neuk ngabangun bumi, kudu kumaha, ieu carana urang, laju ti masyarakat Ayeuna mah lelemah bae, atos ngalelemah, ukuan sabaraha meter nu abah $9 \times 24 \mathrm{~m}$ sok $k u$ abdi dipasihkeun rincian 'oderan' ka tukang kayu, tah tukang kayu, pangalakeun tihang gagalur, papan, laju galar, layeus, lambaran, hateup injuk, talupuh, darurung, sarang, lapok, talupuh, laju ku abdi dibagikeun".

Artinya:

"Untuk membangun rumah Abah (Imah Gede) harus musyawarah terlebih dahulu, semua kokolot lembur yang menganut kepada Abah Asep datang. Abah: "Abah akan membangun Imah Gede ini. Bagaimana caranya, bagaimana masyarakat akan membantu, sekarang kita membuat lelemah terlebih dahulu. Nanti setelah selesai ngalelemah kita tentukan ukuran rumah Abah yaitu 9x24m. Tukang Bas memberikan rincian kepada tukang kayu yang akan menebang di hutan untuk memenuhi kebutuhan tiangtihang gagalur, papan, galar, layeus, lambaran, hateup injuk, talupuh, darurung, sarang, lapok, talupuh".

Musyawarah biasanya dilaksanakan di rumah Abah. Setelah musyawarah disepakati bersama, maka pelaksanaan tahapan pertama segera dimulai. Untuk memulainya biasanya seluruh warga diberitahu terlebih dahulu bahwa Imah Gede akan direnovasi sesuai dengan kesepakatan yang telah dilaksanakan di rumah Abah. Pada hari dan jam yang telah ditentukan seluruh warga berkumpul di rumah Abah, dengan aba-aba atau perintah dari Abah dan para kokolot lembur, dimulailah pekerjaan membongkar Imah Gede. Lahan rumah yang telah dibongkar kemudian dibereskan oleh seluruh warga untuk membuat lelemah baru dengan mempergunakan cangkul.

Pelaksanaan ngalelemah biasanya dapat dilakukan dalam satu hari. Setelah selesai ngalelemah, di hari berikutnya para kokolot lembur dan tukang bas berkumpul kembali di imah rurukan tempat Abah.Di sini mereka bermusyawarah untuk memulai menebang kayu di hutan sesuai dengan kebutuhan yang telah diajukan oleh tukang bas.

Pada hari yang telah ditentukan, warga yang akan melaksanakan penebangan kayu, pertama-tama berkumpul di halaman rumah Abah, seorang sesepuh yang mengepalai penebangan kayu membacakan doa atau $S a d u$ buhun untuk pergi ke hutan yang berbunyi,

Doa pergi ke hutan :

Sadu buhun,

pun pun pun, sang kamarua sang kama rupa

Sarupa rupaning nu ngageugeuh lebak, pasir, cai, kayu, batu,

di dieu kaula neda rek asup ka leuweung bade ngala kayu....sababaraha jalmi, ulah hiri dengki ka putuna adam, umatna kangjeng Nabi Muhamad, birohmatika ya arahaman rohimin. (Sesepuh memulai melangkahkan kaki diikuti yang lainnya)

Artinya:

(Mohon maaf, sang kamarua, sang kamarupa

Semua pengisi jurang, gunung, air, kayu, batu

Kami memohon akan memasuki hutan akan menebang kayu... Beberapa orang, jangan mengganggu kepada umat Adam

Umat Nabi Muhammad

birohmatika ya arahaman rohimin)

Apabila mereka kemalaman di hutan, maka sadu buhun pun harus dibacakan kembali dan ada semacam permohonan kepada pengisi hutan untuk bermalam dan memohon untuk tidak saling mengganggu. 
pun pun pun, sang kamarua sang kama rupa

Sarupa rupaning nu ngageugeuh lebak, pasir, cai, kayu, batu,

di dieu kaula neda rek asup ka lwuweung bade ngala kayu

(sebutkeun rek ngawengi)

sababaraha jalmi ulah hiri dengki ka

putuna adam

umatna kangjeng nabi Muhamad,

birohmatika ya arahaman rohimin

Artinya:

(Mohon maaf, sang kamarua, sang

kamarupa

Semua pengisi jurang, gunung, air, kayu, batu

Kami memohon akan memasuki hutan akan menebang kayu

(sebutkan berapa malam) beberapa orang, jangan mengganggu kepada umat Adam

Umat Nabi Muhammad

birohmatika ya arahaman rohimin)

Sadu buhun untuk memasuki hutan,

Nini Koronjo Kosong, Aki Koronjo

Kosong,

pangosongkeun jalan aing ti dieu ka

leuweung... (baru melangkahkan kaki)

Artinya:

Nini Koronjo Kosong, Aki Koronjo

Kosong

Tolong kosongkan jalanku dari sini ke

hutan... (baru melangkahkan kaki)

sadu buhun untuk memulai menebang kayu,

Pun pun pun,

sadi buhun sang sedarua sang

sedarupa

sarupa rupane anu ngageugeuh lebak

pasir kayu

di dieu kaula adeuk carita ngarah kayu, ulah hiri ulah dengki ulah jail kaniaya

bisi samar kaula incu putu (sebutkeun

ka saha bapa ngolotkeun)

bisi samar kaula incu putu kuring si

anu ....rek nuar kayu....

Artinya:

Pun, pun, pun,
Sadi buhun, sang sedaruasedarupa

Semua pengisi jurang, gunung, kayu

Di sini kami akan memohon menebang

kayu

Jangan mengganggu

Bila tidak tahu saya cicit dari ....

(sebutkan orang yang dituakan)

Bila tidak tahu saya cicit saya si ....

(sebutkan nama) memohon menebang

kayu ....(sebutkan kayu jenis apa)

Setelah kayu-kayu ditebang, lalu digergaji dijadikan balok-balok sesuai ukuran yang diperlukan, seperti untuk membuat lambaran, lapok, tihang, gagalur, papan, galar, layeus, gagalur, darurung, papan. Begitu pula penebangan pohon bambu dilakukan sesuai dengan kebutuhan, untuk membuat bilik, sarang, ereng, dan talupuh. Penggergajian kayu untuk membuat balokbalok, semuanya dikerjakan di hutan selama beberapa hari. Seperti yang diungkapkan oleh Bapak Saidi (Tukang Bas), ketika penggergajian kayu-kayu di hutan selesai,

"Tos milarian di leuweung cara nyandakna gotong royong, tos diragaji, laporan ka abah, bah itu tos beres di leuweung, abah mere bejaan $\mathrm{ka}$ tiap olot lembur deui, poe anu neang kayu, bring nyandak kayu dua ratus orang, terus didamelan, tihang, nyuguan, lambaran, ngadamel panto, abdi mah nyabakna teu pati, seueur, lambaran teh pamikul, gagalur, saurang nyieun panto, dibagi-bagi lamun teu dibagibagi lami”.

Artinya:

Setelah semua pekerjaan di hutan selesai, cara membawanya ke kampung harus gotong royong. Tukang kayu memberi laporan kepada Abah bahwa pekerjaan sudah selesai, Abah memberi tahu kepada semua kokolot lembur menentukan hari untuk mengambil kayu.Kemudian sebanyak 200 warga berangkat ke hutan untuk mengambil kayu. Kayu-kayu tersebut dikerjakan untuk memenuhi kebutuhan. Saya sebagai tukang bas tidak banyak kerja, 
hanya mengawasi saja, pekerjaan dibagi-bagi kepada ahlinya untuk membuat pintu, lambaran, gagalur, agar lebih cepat selesai.

Balok-balok kayu yang telah selesai dikerjakan dibawa ke kampung untuk dikeringkan di halaman rumah, atau disandarkan di dinding tebing.

Tahap selanjutnya adalah ngabobohan, kegiatan membuat berbagai tiang dan galar untuk membuat rangka rumah.Ngabobohan adalah proses setelah bilahan kayu yang diangkut dari hutan dijadikan tiang, papan, galar, menyerut kayu agar halus, membuat cowakan, menggergaji untuk menambah dan memotong kayu, menyambung kayu untuk pangeret, membuat daun jendela, daun pintu, dan menyerut papan untuk tataban.Setelah pekerjaan tersebut selesai maka dilanjutkan dengan tahapan berikutnya yaitu ngarangki.

Tahapan ngarangki adalah ngarangkay semua kayu untuk dijadikan rangka rumah. Pekerjaan membangun Imah Gede merupakan sebuah kerja sama antara Abah sebagai orang yang akan menempati rumah tersebut, dukun, penghulu, tukang bas dan pembantunya. Abah yang memberi perintah untuk melakukan pembangunan dan merestui semua pekerjaan, sementara dukun menghitung hari-hari baik bersama Abah untuk menentukan kapan memulai semua pekerjaan berdasarkan weton Abah. Penghulu, adalah orang yang selalu membacakan doa-doa dan menyiapkan sesajen dari awal hingga akhir pekerjaan. Tukang bas, menyiapkan pekerjaan dalam merangkai dan membuat rangka rumah dibantu oleh pembantunya membuat berbagai tiang dan keperluan lainnya, seperti membuat daun pintu, galar, daun jendela. Abah yang merestui pekerjaan diharapkan bahwa semua pekerjaan akan berjalan lancar dan tidak ada halangan apapun yang menimpa kepada seluruh pekerja juga nantinya setelah rumah selesai dibangun yang akan memberi berkah kepada pengisi rumahnya.
Sama halnya dengan membangun rumah penduduk, membangun Imah Gede pun tidak boleh pada bulan Maulud dari tanggal 1 sampai tanggal 15 dan bulan Sapar dari tanggal 15 sampai tanggal 30. Hal itu disebabkan karena pada bulan Maulud adalah bulan kelahiran Nabi Muhammad sedangkan pada bulan Sapar merupakan bulan kawin anjing. Perhitungan untuk menentukan awal pembangunan dihitung berdasarkan weton Abah, agar jiwa Imah Gede sesuai dengan orang yang akan menempati rumah dan tidak menimbulkan masalah seperti sakit, rezeki, dan keselamatan juga keberkahannya. Untuk memulai pekerjaan, biasanya semua peralatan yang diperlukan dalam membangun rumah dikumpulkan kemudian didoakan oleh penghulu dan Abah agar alat-alat tersebut tidak bermasalah sewaktu dipergunakan.

Kegiatan ngarangki atau merangkai dimulai dari memasang rangka paling selatan, letak puhunya (pangkal) berada di selatan, congo (ujung) ada di utara, letak pintu tergantung pada weton suami, di sini Abah sebagai kepala keluarga dan sesepuh Kasepuhan, letak Padaringan (goah) berdasarkan perhitungan istri (Ambu, sebagai istri Abah). Untuk pemasangan tiang, biasanya puhu di bawah dan bisanya di atas tatapakan atau umpak dari batu citak harus ada cicis yaitu uang logam (berapapun nilainya), maknanya untuk tunggul kuras yang berkaitan dengan kemudahan untuk mencari rezeki dan keluarga yang tidak kekurangan dalam hal ekonomi; congo ada di atas. Kiasan ini memberi simbol ibu yang mengandung anak, ibu seperti puhu lebih kuat harus berada di bawah, sedangkan congo adalah anak harus berada di atas. Makna lainnya adalah dilambangkan pada pertumbuhan padi, pangkal adalah ibu dan buah adalah anak. Pemasangan tiang bisanya ditentukan dan sangat diperhatikan waktunya sesuai dengan perhitungan berdasarkan weton suami, yang harus jatuh pada nilai jaya. 
Peribahasa papuhu pacongo adalah menempatkan sesuatu yang seharusnya pada tempatnya, begitu pula dalam penempatan tiang-tiang tidak boleh sembarangan memasangkan dan menempatkan, mana puhu dan mana congo harus benar-benar diperhatikan. Apabila tidak diperhatikan dengan benar maka akan menimbulkan malapetaka bagi semua orang baik yang mengerjakan maupun nantinya kepada orang yang mengisi rumah. Tiang-tiang yang harus diperhatikan penempatan puhu dan congo di antaranya adalah tiang adeg, tiang langsung, usuk, talupuh, papan. Penempatan mana puhu dan mana congo menunjukkan bahwa mana awal dan mana akhir merupakan bagian yang sangat penting tidak boleh dirempak (dilanggar). Misal untuk penempatan bagian tiang yang berdiri, puhu harus disimpan di bagian bawah dan congo di bagian atas, sedangkan untuk batang yang melintang, maka puhu harus ditempatkan dibagian depan dan congo di bagian belakang.

\section{a. Nanjeurkeun (mendirikan bangunan)}

Proses ini dimulainya menempatkan sejumlah tatapakan yang akan dipergunakan sebagai tumpuan tiang atau gagalur. Untuk memulainya tidak lupa waktu yang telah ditetapkan berdasarkan hitungan weton suami (Abah) yang akan menempati Imah Gede. Peletakan ruang Padaringan harus disesuaikan dengan weton istri (Ambu) letaknya di sisi barat atau sisi timur. Hal ini untuk menentukan congo harus terletak di sini. Letak pintu harus disesuaikan dengan weton suami (Abah) di sini diletakkan puhu. Penempatan puhu dan congo ini menjadi keharusan yang diperhatikan dengan benar bisi papuhu pacongo artinya jangan salah menempatkan mana pangkal mana ujung.

Untuk memulai memasangkan tatapan yang akan dijadikan tumpuan umpak biasanya tukang bas membacakan sadu buhun yang disebut sadu buhun kasemaran terlebih dahulu. Sadu buhun kasemaran maknanya doa untuk memberi daya tarik rumah, walaupun sederhana tapi selalu menarik. Sadu buhun untuk memulai memasangkan tatapakan adalah :

Semar aing semar kuring,

semar aing bulu munti,

malik ka lubang jaya,

mangkurat mangkaret mangkubumi,

pangeran mangku nagara

aing ka semar

semar badan awaking nu asih ka badan

awaking. (Nembe pasang tatapakan).

Artinya:

Semar aku semar saya

Semar aku bulu munti

Kembali ke lubang jaya

Mangkurat mangkuret mangkubumi

Pangeran mangkunagara

Aku kepada Semar

Semar badanku yang sayang kepadaku

(kemudian memasangkan tatapakan)

Patokan papuhu pacongo menjadi pegangan agar tidak salah dalam menerapkan bahan-bahan yang akhirnya akan menimbulkan malapetaka bagi pengisi rumah dan pekerja. Untuk itu Tukang bas sangat berperan dalam menentukan mana puhu dan mana congo dalam pemasangan berbagai tiang dan kayu-kayu yang lainnya. Tiang harus dipasang pada puhu di bawah dan congo berada di atas. Begitu pula dengan tiang yang dipasang horizontal puhu harus dipasang di depan dan congo di belakang. Sistem penyambungan kayu, harus pula diperhatikan bila kayu kurang panjang maka congo harus disambungkan dengan bagian puhu, yang nantinya congo tetap berada di belakang.

Khusus untuk pemasangan rangka Imah Gede, Puhu dipasang di depan kemudian congo berada di belakang, baik untuk pemasangan lambaran yang letaknya horizontal yang berada di atas puhu harus berada di sebelah timur dan congo berada di sebelah barat. Tukang bas dan tukang kayu yang menebang kayu harus lebih hati-hati dalam menentukan penyambungan dan awal menebang, karena ketika akan di bawa ke kampung, harus jelas mana kayu-kayu puhu dan 
mana congo disimpan dengan baik. Tukang kayu dan tukang basakan menentukan dalam segala hal, seperti membuat daun pintu dan daun jendela dan membuat galar (kosen). Pemasangan ereng di atas puhu dan congo dipasangkan ereng pertama harus puhu di atas congo di bawah, baru kemudian ereng kedua congo di atas puhu di bawah, hal ini agar ereng terlihat rata.

\section{b. Mendirikan Rumah}

Ada dua macam proses yang terjadi dalam mendirikan rumah, pertama proses membangun yang berhubungan dengan teknis pembangunan rumah dan nyuhunkeun bahan (meminta restu) yang berhubungan dengan sistem kepercayaan dalam proses membangun. Nyuhunkeun bahan selalu dilakukan pada setiap tahapan yang akan dilewati dalam membangun rumah.

Membangun rumah adalah sebuah proses ritus yang harus memenuhi berbagai persyaratan adat. Mulai dari awal persiapan untuk mempersiapkan bahanbahan hingga penempatan rumah itu sendiri adalah ritus yang dilaksanakan penuh dengan kehati-hatian.Biasanya dalam mendirikan sebuah bangunan rumah, masyarakat sekitar ikut bersama bergotong-royong.Pembangunan sebuah rumah diawali dengan : (a) Nyuhunkeun bahan (meminta restu), (b) Babahan (pengumpulan bahan), (c) Ngalelemah (meratakan tanah), (d) Milari dinten nu sae (menetapkan hari baik), (e) Ngawitan nuar kayu (memulai menebang kayu), (f) Ngabobohan (merangkai kayu), (g) Nanjeurkeun (mendirikan rumah), (h) Ngabenteng, dibalay (membuat benteng).

\section{c. Nyuhunkeun bahan (meminta restu)}

Pembangunan sebuah rumah diperlukan beberapa tahapan yang dilaksanakan secara adat. Pertama-tama pemilik rumah akan datang menjambangi Abah sebagai tutunggul atau yang dituakan, dengan membawa kemenyan dan panglay (Zingiber Cassummunar roxb).
Maksud dan tujuannya adalah meminta izin dan restu sekaligus berkah dalam niatan membangun sebuah rumah. Setelah diizinkan dan diberi bahan, bahan tersebut dipetakeun (bahan, biasanya berupa kemenyan dipetakeun, artinya kemenyan dibakar dan panglay dikunyah kemudian disemburkan ke tanah yang akan dibangun). Upacara salametan dengan cara membakar kemenyan dan menaburkan panglay dilaksanakan di rumah atau di pelataran yang akan dibangun rumah.

Nyuhunkeun bahan ini dilakukan pada setiap tahapan pekerjaan membangun rumah dari awal hingga akhir, mulai dari ngalelemah (meratakan tanah), ngawitan barang ala (menebang kayu),ngarangki (memasang-masangkan kayu), nanjeurkeun (mendirikan tiang) dan ngeusian imah (menempati rumah). Nyuhunkeun bahan itu menjadi penting untuk pelaksanaan kegiatan agar pemilik rumah maupun yang akan mengerjakan pembangunan terjaga keselamatannya dan mendapat berkah dari Allah SWT. Untuk memulai menebang pohon, si pemilik hajat harus nyuhunkeun bahan kembali kepada Abah, agar keselamatan tetap terjaga dan tidak terjadi sesuatu yang diharapkan. Bahan ini dipetakeun di hutan agar segala makhluk halus penghuni hutan dapat menjaga keselamatan orang-orang yang akan melaksakan pekerjaan itu.

Tahap selanjutnya menghadap ke dukun untuk milarian dinten nu sae (menentukan hari baik) untuk memulai kegiatan. Milarian dinten nu sae biasanya dihitung menurut perhitungan hari baik yang dapat dilihat dari hari repok yaitu kecocokan hari dan tanggal kelahiran si pemilik rumah memulai kegiatan. Perhitungan hari baik tidak saja untuk menentukan kapan dimulai pembangunan juga dilakukan untuk memulai barang ala, memulai nanjeurkeun, dan kapan waktunya untuk ngeusian imah (menempati rumah). Hal tersebut dilakukan sesuai dengan ketentuan dan adat istiadat yang berlaku. Apabila salah satu tahap tidak dilaksanakan maka akan memberikan 
akibat yang tidak diinginkan. Seperti yang dikatakan Abah (Sesepuh Kampung Sinar Resmi), bahwa: "Ngalanggar aturan teu siga ngadahar cabè, tèp tèwèwèw, kè biasana geus poho kana naon anu dipigawè, kakara dièlingkeun" (melanggar aturan tidak seperti memakan buah cabai yang langsung terasa, nanti apabila sudah lupa, baru akan terasa akibatnya). Ketika ada orang yang sakit tiba-tiba, maka harus dicari penyebabnya dan apa kesalahan yang telah diperbuat. Dukun biasanya akan membantu mencari penyebab sakitnya. Salah satu contohnya yaitu apabila orang terkena penyakit pada hari Kamis, biasanya berhubungan dengan perbuatan melanggar tatakrama kepada sri (padi); bila hari sakitnya datang pada hari Selasa berhubungan dengan rumah atau pekarangan atau sesuatu yang berada di luar rumah. Sedangkan orang yang terkena sakit pada hari Sabtu biasanya berhubungan dengan kesalahan pada hurip yaitu ada pelanggaran pada tata cara membangun rumah. Untuk penyembuhannya, dukun akan memberikan wejangan agar harus cepatcepat bertobat untuk datang kepada Abah melaksanakan bèbèrès (membersihkan diri) dengan sebuah ritual adat.

\section{d. Tahap Babahan (Pengumpulan B ahan)}

Kata bahan dalam frase nyuhunkeun bahan dengan frase Tahap babahan berbeda arti dan maknanya. Kata babahan berasal dari kata bahan yang artinya bahan material yang akan dijadikan barang jadi, ditambah rajèkan (kata ulang) "ba-" yang menunjukkan makna kata kerja berarti mengumpulkan semua bahan material yang diperlukan dalam pembangunan rumah. Kata bahan frase meminta bahan berarti "sesuatu yang bersifat immaterial berupa doa dan restu" terkandung maksud juga mempersiapkan secara spiritual sebelum pembangunan rumah. Sedangkan kata bahan dalam babahan adalah "sesuatu yang bersifat material atau benda"

Setelah tahap awal yaitu nyuhunkeun bahan dilewati, tahap selanjutnya adalah tahap babahan yaitu tahap yang akan dilaksanakan oleh si pemilik rumah untuk mengumpulkan bahan-bahan material. Ketika akan memulai pembangunan sebuah rumah, si pemilik datang kepada tukang bas (orang yang ahli membangun rumah), untuk membicarakan tata cara pembangunan rumah yang sesuai dengan permintaan. Biasanya, dibicarakan segala sesuatu yang menyangkut pembangunan, mulai dari gaya rumah, luas rumah, bahanbahan yang dibutuhkan, kapan dan berapa lama pembangunan akan dilaksanakan. Setelah pembicaraan disepakati, pemilik hajat harus mengumpulkan bahan-bahan atau disebut dengan istilah babahan.

Lamanya pengumpulan bahan atau babahan tergantung dari kesiapan si pemilik rumah, biasanya babahan dilakukan secara menyicil mulai mengumpulkan bahan kecil awi 'bambu' untuk erèng yang harus dikeueum 'direndam' di dalam kolam yang memakan waktu lama, atau memotong kayu di hutan dan menggergajinya menjadi bagianbagian tertentu untuk tiang, mengumpulkan hateup, ijuk dan material lainnya.

Ada sebagian bahan bangunan yang harus dibeli dan menebang sendiri, seperti kayu untuk usuk atau kaso. Batu tatapakan citak, hateup dan ijuk dibeli dari Kampung Cicadas. Bahan-bahan babadag (kayukayu besar), seperti papan, tihang pangeret, lambaran, galar, hateup, injuk dan bilik harus dibeli dari toko material. Batu tatapakan yang berbentuk lempar 'bulat rata' dapat diambil dari sungai Cibareno.

Kegiatan babahan ini dilakukan sesuai dengan kebutuhan, sehingga si pemilik rumah dapat memperkirakan berapa biaya yang diperlukan. Misalnya untuk membangun rumah dengan ukuran $5 \mathrm{~m} \times$ 9 , diperlukan jumlah hateup 400 jalon dengan harga per-jalon Rp. 2.000,00, ijuk 500 kakab@ Rp. 3000,00, kayu untuk tihang sebanyak 28 batang dengan ukuran $12 \mathrm{~cm} \times 12 \mathrm{~cm} \times 3 \mathrm{~m}$, kayu pangeret atau pamikul sebanyak 18 batang ukuran 
$12 \mathrm{~cm} \times 12 \mathrm{~cm} \times 6 \mathrm{~m}$, kayu lambaran 12 batang dengan ukuran $12 \mathrm{~cm} \mathrm{x} 12 \mathrm{~cm} \mathrm{x} 4 \mathrm{~m}$, kayu galar 180 batang dengan ukuran $6 \mathrm{~cm}$ x $12 \mathrm{~cm}$ x $3 \mathrm{~m}$, papan untuk lantai, panto, lapok, lincar, tutup usuk dan lisplang sebanyak 180 lembar dengan ukuran $3 \mathrm{~cm} \mathrm{x}$ $20 \mathrm{~cm} \times 3,5 \mathrm{~m}$ kayu untuk kaso-kaso sebanyak 168 batang dengan ukuran $6 \mathrm{~cm} \mathrm{x}$ $6 \mathrm{~cm} \times 3 \mathrm{~m}$, talupuh untuk lantai di dapur sebanyak 18 buah, darurung sebanyak 18 batang, dan sarang 62 batang bambu, bilik sebanyak 66 geblèg (lembar). Talupuh dibuat dari satu batang bambu harganya Rp10.000, dapat dijadikan dua lembar talupuh, dengan ongkos untuk pembuatnya perhari Rp. 30.000. Pembuatan talupuh dalam satu hari dapat menghasilkan lima hingga sepuluh lembar. Keperluan lainnya seperti, kaca, paku, bisa membeli di toko material dengan harga yang bervariasi sesuai harga pada waktu pembelian. Bahan-bahan yang telah siap untuk rangka rumah, kemudian diolah pada waktu hari yang telah ditentukan.

Untuk keperluan membangun rumah, biasanya akan memilih kayu bagus yang lurus, maka secara bergotongroyong pergi ke hutan untuk menebang kayu. Tidak sembarangan jenis kayu yang dapat dipergunakan sebagai bahan bangunan, mereka akan memilih jenis kayu seperti Surèn, Jèngjèn, KiSèrèh, Kapidengkung, dan lain-lain. Penebangan kayu disesuaikan dengan kebutuhan dan tidak boleh menebang kayu dari hutan tutupan dan hutan larangan.

Ada beberapa pantangan yang harus dipatuhi apabila akan mengambil kayu dari hutan, yaitu tidak boleh mengambil:

a. kayu yang telah rubuh atau disebut eunyeuh.

b. pohon kayu yang meranggas atau disebut pugur.

c. kayu bergetah gatal atau disebut balas.

d. Kayu Rasamala, menurut kepercayaan penduduk Kampung Sinar Resmi, kayu ini memiliki makna yang jelek, kata mala menunjukkan arti mara bahaya bagi pemilik rumah.

e. pohon kayu reungas. f. pohon Belendung.

g. pohon yang terbawa longsor.

h. pohon roboh (roboh karena tertiup angin).

i. pohon yang potong tengahnya (kai $n u$ punggel tengahna).

$j$. pohon sisa penebangan orang ( $k a i$ galong berarti celaka, apabila digunakan untuk rumah, maka akan membawa petaka bagi si pemilik rumah.

k. Kayu yang telah ditebang orang lain. (panuaran urut batur).

Kayu-kayu yang telah ditebang dan digergaji sesuai dengan kebutuhan kemudian dikeringkan dengan cara disandarkan pada dinding. Apabila sudah dianggap kering, kemudian disimpan di kolong rumah atau pipir yang ada di belakang rumah, bahkan ada pula bahan material ini di simpan diteritisan rumah lama yang akan dibongkar.

\section{e. N galelemah (Meratakan Tanah)}

Ngalelemah adalah proses awal dari pembangunan sebuah rumah. Ngalelemah artinya meratakan tanah yang akan dijadikan lahan pembangun rumah baru, kemudian menentukan tempat tatapakan untuk tiang-tiang soko atau tiang-tiang pokok.

Tanah yang dijadikan lahan untuk rumah ini, bisa lahan lama dari rumah yang dibongkar atau membuat lahan baru. Untuk kelancaran proses meratakan tanah ini, si pemilik rumah biasanya datang terlebih dahulu kepada Abah untuk meminta berkah atau disebut nyuhunkeun bahan, biasanya Abah memberi kemenyan untuk dibakar di lahan yang akan dijadikan rumah dan panglay untuk ditaburkan di pelataran tersebut. Fungsi kedua bahan ini untuk mengusir makhluk halus yang akan mengganggu nantinya atau diperkirakan ada makhluk halus yang akan terganggu, agar tidak mengganggu. Dengan demikian pemilik rumah dan para pekerja terjaga keselamatannya dari gangguan makhluk tersebut. Di samping itu dengan nyuhunkeun bahan ini dimaksudkan agar 
pemilik maupun pekerja diberi keberkahan dari karuhun dan Allah SWT.

Kebiasaan yang dilakukan di Kasepuhan Sinar Resmi, dalam proses ngalelemah ini diawali dengan membongkar rumah yang lama, kemudian tanah bekas rumah tersebut dibereskan dan dibersihkan kembali, proses ini disebut ngalelemah. Tanah yang rumahnya telah dibongkar tadi dibuat lebih tinggi dari tanah asalnya setinggi $15 \mathrm{~cm}$ sampai dengan $20 \mathrm{~cm}$, kemudian tukang bas mencari titik tertentu untuk menetapkan batu tatapakan disimpan sebagai penopang tiang atau gagalur. Posisi ini sesuai agar soko atau tiang penyangga dapat berdiri dengan tegak (tidak terbenam ke dalam tanah) (Adimiharja, 1986:75) Tahap ini disebut ngadegkai (peletakan batu pertama (Team Pra Penelitian Arsitektur Tradisional di Indonesia, 1982).

\section{f. Milarian Dinten nu Sae (Menetapkan Hari Baik)}

Milarian dinten nu sae (menghitung atau menetapkan hari baik), proses ini merupakan proses umum yang dilakukan oleh masyarakat Kampung Sinar Resmi dalam segala hal, baik itu pekerjaan, perjalanan maupun mencari nafkah. Dalam hal membangun rumah, perhitungan dilakukan sebelum pembangunan dilakukan, biasanya milarian dinten $n u$ sae, dilakukan untuk menentukan kapan dimulainya pekerjaan, ngalelemah, ngala kai, nanjeurkeun, dan ngeusian imah. Setiap warga masih menaati kepercayaan ini dalam perhitungan-perhitungan untuk menentukan hari baik yang dihitung berdasarkan hari kelahiran suami.

\section{g. N gawitan Nuar Kai (M ulai Menebang Kayu)}

Penebangan pohon kayu yang akan dilakukan di hutan, biasanya selalu dihitung berdasarkan weton si pemilik rumah (suami). Dengan dikepalai penghulu yang membawa bahan dari Abah, diiringi orang-orang yang akan membantu menebang, mereka berangkat ke hutan untuk mencari kayu yang diperlukan. Untuk memulai menebang pohon, penghulu membacakan doa-doa dan membakar kemenyan (bahan) dari Abah. Setelah itu baru menebang pohon sesuai kebutuhan.

Memotong kayu untuk dijadikan balok, dilakukan di hutan dengan gergaji besar yang dikelompokkan berdasarkan kebutuhan untuk membuat lambaran, gagalur, tihang, ander, lakop, papan, dan lain-lain. Balok-balok kemudian diangkut ke kampung dan dijemur sampai kering.

\section{h. Ngabobohan (Merangkai Kayu)}

Ngabobohan adalah mengerjakan semua kayu untuk diserut menjadi rapih, membuat papan, membuat tiang, menyambung tiang, membuat daun pintu, membuat daun jendela, membuat talupuh, membuat bilik, dan menyiapkan semua bahan yang siap untuk dipasangkan.

\section{i. N garangki (M emasangkan Kayu)}

Tahapan ngarangki atau ngarangkay kayu, disebut juga dengan masangkeun kayu dengan kayu yaitu memasangkan kayu-kayu untuk dijadikan tihang 'tiang' atau rangka rumah yang lainnya. Proses ngarangki kayu adalah proses memasangkan kayu-kayu menjadi rangka rumah dari bawah (tiang/gagalur) hingga atas (atap). Semua pekerjaan membuat kerangka kayu dan masangkeun kayu biasanya dilaksanakan di atas tanah yang telah dilelemah 'diratakan' atau di buruan, di luar curugan cihujan (pinggir-pinggir rumah) di sekitarnya. Hal tersebut dilakukan untuk mempermudah pemasangan dan nanjeurkeun tiang kayukayu yang telah dirangki.

\section{j. $\mathrm{N}$ anjeurkeun Imah (M endirikan Rumah)}

Bulan Mulud tanggal 1 sampai dengan tanggal 15 dan Bulan Sapar dari tanggal 15 sampai dengan tanggal 30 tidak boleh membangun rumah. Di Kampung Sinar Resmi hanya hari Jumat yang dianggap hari paling baik untuk melakukan segala pekerjaan membangun, hari Jumat dianggap paling baik, disebabkan karena 
adanya pengaruh Rajah Bumi.Namun kebalikannya untuk aktivitas bertani tidak boleh dilakukan, sebab apabila terjadi kecelakaan menyebabkan luka yang sangat parah.

Seperti apa yang diungkapkan oleh tukang bas, bahwa : "Dinten nu alus tèh poè jumaah nu paling saè. Nanjeurkeun bumi, nyieun bumi, ngadamel naon bà̀ ngalebetan bumi, asal dinten jumaah, badè ngalelemah, badè ngadamel astana, arèk lumampah naon baè. Jumaah tèh hasil tina akibat rajah bumi” (Hari yang baik itu adalah hari Jumat, untuk pekerjaan mendirikan rumah, membuat apa saja, mengisi rumah baru, meratakan tanah, membuat astana, bepergian. Jumaah itu baik karena adanya rajahbumi) Rajah bumi berbunyi:

banyu ahèng nètèsna dipoè Jum'ah, sabda wenang namanya

batu ahèng nètèsna di poè Saptu sabda tu namanya

kayu ahèng nètèsna di poè Ahad, sabda kala namanya

bayu ahèng nètèsna dipoè Senèn, sabda guru namanya

sang nata nata, sang nata prang wadana, hurip ku tampa bayanè.

Artinya:

(air suci menetes pada hari Jumat, sabda wenang namanya,

Batu suci menetes pada hari Sabtu, sabda tu namanya,

Kayu suci menetes pada hari Minggu, sabda kala namanya,

Angin suci menetes pada hari Senin, sabda guru namanya,

Sang nata-nata sang nata prang wedana, kehidupanku terima semuanya)

Hari lahir suami adalah awal membangun rumah, maka pada waktu yang telah ditentukan tersebut, semua peralatan dan material disimpan di atas lelemah. Panghulu membacakan doa, membakar kemenyan dan menaburnaburkan panglay (bahan) dari Abah. Doa yang diucapkan diambil dari Al'Quran. Ikrar doa yang diucapkan sama dengan ikrar pada waktu akan memasuki rumah baru yang telah selesai dibangun, seperti :

Ikrarna bade ngadamel bumi: bisi papuhu pacongo, bilih aya sato hèwan anu kaganggu nuju ngadamel ieu bumi, neda hampura, salamet kanu ngadamelanana, salamet bumina, salametna anu ngeusian bumi.

Artinya:

(Ikrar untuk membangun rumah:Takut ada yang terbalik, kalau-kalau ada hewan dan binatang yang terganggu sewaktu membangun rumah ini, kami memohon maaf selamat kepada yang bekerja, selamat kepada yang memiliki rumah yang akan mengisinya).

Dimulai dengan memasangkan tiang-tiang yang disambungkan dengan balok horizontal setinggi dada orang tua dan galar (kosen) jendela, di bagian atas dipasang tiang-tiang yang saling dihubungkan dengan pangeret dan lambaran. Pemasangan seterusnya adalah memasang tiang ander dan suhunan dihubungkan dengan tiang sogol yang menyangga tiang ander. Setelah itu baru pemasangan layeus, di atasnya dipasang erèng (atau disebut ngerèng) yang jaraknya $15 \mathrm{~cm}$, baru kemudian dipasang hateup (jalon dan ijuk). Pemasangan atap rumah biasanya dilakukan secara bergotongroyong oleh warga. Apabila rangka rumah telah tertutupi oleh atap, maka pekerjaan dianggap selesai.

Tahap selanjutnya, dilanjutkan ke bagian tengah yaitu pemasangan lantai atau tataban yang terbuat dari bilah papan. Dilanjutkan dengan pemasangan galar (kosen) baik jendela maupun pintu. Setelah pemasangan galar selesai baru kemudian pemasangan dinding atau bilik, biasanya dilakukan secara bergotong royong.Untuk menambah kekuatan bilik yang menempel pada tiang-tiang, harus mempergunakan lapok atau cempèd yang terbuat dari kayu atau bambu selebar $5 \mathrm{~cm}$ yang dipakukan pada tiang. Pemasangan selanjutnya jendela dan terakhir adalah pemasangan daun pintu. Nanjeurkeun rumah dianggap selesai. 
Untuk memulai nanjeurkeun, secara adat diperlukan perhitungan-perhitungan yang harus ditaati. Perhitungan ini berdasarkan perhitungan palintangan yang dikenal dengan istilah pancer lima, perhitungan palintangan pancer lima adalah:

a. Nilai 1 Kuta: baik untuk membuat saung lisung;

b. Nilai 2 Kusang: baik untuk membuat kandang hewan;

c. Nilai 3 Naga: baik untuk membuat leuit;

d. Nilai 4 Gelar: baik untuk membuat bale pertemuan, masjid;

$e$. Nilai 5 Jaya: baik untuk membuat rumah.

Cara menghitungnya dengan rumusan sebagai berikut: misalkan hari kelahiran naktu: wedal suami, (kelahiran suami) adalah hari Minggu tanggal 20. Hari Minggu. Akan memulai nanjeurkeun pada hari Minggu, maka perhitungannya, hari Minggu nilainya lima (5). Ada patokan nilai untuk menentukan nilai setiap harinya, seperti: Senin nilainya 4, Salasa nilainya 3, Rabu nilainya 7, Kamis nilainya 8 , Jumat nilainya 6 , Sabtu nilainya 9, dan Minggu nilainya 5. Untuk menentukan kapan nanjeurkeun, maka perhitungannya sebagai berikut: Wedal suami hari Minggu nilainya 5, bulan April tanggal 20. Nilai hari Minggu ditambah dengan tanggal kelahiran, yaitu tanggal 20 menjadi $(5+20=25)$ kemudian jumlah 25 dibagi jumlah hari yang 7 (Senin sampai dengan Minggu), hasilnya 3 ada sisa 4; Nilai 4 jatuh pada naga, (naga, sesuai dengan palintangan yang ada diperuntukkan untuk membangun leuit, sedangkan jumlah nilai untuk membangun rumah harus 5, yang artinya jatuh pada "jaya") Untuk mencapai jumlah 5 harus ditambah 1. Nilai (1) satu dapat diganti dengan menunjukkan pada waktu atau jam 1 (satu). Jadi nanjeurkeun harus dilakukan pada hari Minggu pukul 1 (satu).

Perhitungan repok pada umumnya di daerah Jawa Barat dan di kampungkampung adat biasanya diambil dari nama suami istri ditambah dengan hari kelahiran. Namun tidak demikian bagi masyarakat Sinar Resmi, perhitungan repok diambil hanya dari hari kelahiran saja. Kata repok merupakan akronim dari пи iеu rep пи itu pok (yang satu diam berbicara, yang satu berbicara, yang dapat diartikan ketika suami marah, maka si istri harus diam atau sebaliknya) sehingga aman dan rèpèh (damai). Jadi kecocokan itu bukan masalah nama, tetapi dawuh 'omongan' yang berbeda. Setelah kecocokan perhitungan selesai, nanjeurkeun tiang dilaksanakan pada waktu yang telah ditentukan. Apabila tiang sudah berdiri dengan kokoh, maka pembangunan dapat dilanjutkan dengan masangkeun berbagai rangka rumah sehingga rumah cepat berdiri.

Pelaksanaan nanjeurkeun biasanya dikepalai oleh tukang bas yang disesuaikan dengan waktu yang telah dihitung sebelumnya. Nanjeurkeun merupakan kegiatan yang dilakukan secara gotong royong, orang-orang datang dengan sendirinya untuk membantu yang punya hajat, biasanya mereka yang datang tidak dibayar atau menerima upah seperti halnya tukang bas, pemilik rumah hanya menyediakan makan dan rokok ala kadarnya.

Proses nanjeurkeun merupakan proses memasangkan tiang dari balok kayu menjadi sebuah kerangka rumah. Secara adat, di bawah tiang ini harus disimpan cicis uang logam sebagai simbol dari kekayaan. Maksudnya untuk menjaga agar si pemilik rumah selalu memiliki persediaan uang. Pemasangan tiang untuk sebuah rumah yang berbentuk tiang langsung akan berbeda dengan rumah yang berbentuk gagalur. Rumah tiang langsung, adalah rumah yang memiliki sejumlah tiang yang langsung bertumpu pada umpak atau tatapakan batu lempar. Sedangkan rumah berbentuk gagalur, pembuatan tiang dimulai di atas gagalur, sehingga tatapakan atau umpak bertumpu pada gagalur, tatapakan yang dipergunakannya pun adalah tatapakan batu citak. 
Cara pembuatan rumah bergaya gagalur, dimulai dengan memasangkan atau merangki kayu-kayu untuk dijadikan kerangka rumah, jumlah kerangka akan ditentukan dengan deretan tiang. Pemasangan atau perakitan kayu biasanya dilakukan di tempat lelemah yang telah dibuat.Tukang Bas dan warga masyarakat yang lainnya membantu memadukan tiang. Semua tiang yang berada di atas gagalur yang bertumpu pada tatapakan (batu citak) diperkuat atau disatukan dengan kayu yang dipasang horizontal arah panjang disebut lambaran dan arah lebar disebut pangeret. Di atasnya dipasang kayu yang sejajar dengan lambaran dan pangeret tingginya setinggi dada orang tua disebut galar atau umumnya disebut palang dada. Letak galar berada di bawah lambaran dan di atas pananggeuy disatukan dengan kayu vertikal disebut tihang. Sedangkan di bagian bawah pananggeuy dipasang balok kayu antara tiang dengan tiang yang disebut sunduk, gunanya untuk memasangkan darurung. Di atas lambaran dipasang kayu ander untuk menunjang suhunan, kemudian diperkuat dengan kayu jurè yang dipasang miring. Sejajar dengan jurè, dipasang layeus dari batang bambu. Jarak pemasangan layeus dengan layeus yang lain dapat dipasang berjarak $20 \mathrm{~cm}$ hingga $25 \mathrm{~cm}$, begitu pula dengan jumlah layeus disesuaikan dengan lebar rumah. Di atas layeus pasang erèng yang terbuat dari bilahan bambu selebar $5 \mathrm{~cm}$, dipasang berjarak $15 \mathrm{~cm}$ melintang sejajar dengan wuwungan. Sedangkan untuk memperkuat dan memperkokoh tahanan layeus ini di tengah-tengah dipasang balok kayu yang berfungsi menahan layeus disebut palang tinggang. $\quad \mathrm{Di}$ atas ereng kemudian dipasangkan hateup yang diikatkan pada erèng, hateup dipasang mulai dari bawah disusun ke atas, di atasnya baru dipasang ijuk yang berfungsi untuk menguatkan dan menahan lapuk hateup. Di atas wuwungan dipasang batang bambu untuk penguat agar ijuk dan hateup tidak lepas yang disebut dengan kadal meteng. Di ujung wuwungan di atas cablik dibentuk bulatan yang terbuat dari lilitan ijuk yang disebut ijuk dibelengkungkeun (dibulatkan), secara maknawi memiliki makna ngabuleudkeun nu tilu; ucap, tèkad, jeung lampah (membulatkan yang tiga unsur, yaitu perkataan, tekad, dan perbuatan). Di samping itu memiliki makna harus yakin kepada Yang Maha Kuasa, Yang Maha Memiliki.

Teknik untuk memperkuat sambungan antara pangeret dan lambaran atau pananggeuy dan pangeret, ujung pangeret disogot artinya dilubangi empat persegi panjang kemudian tiang ujungnya dibuat empat persegi runcing disebut pupurus fungsinya untuk niir menjadi pasak pangeret dan lambaran atau pananggeuy. Selain itu teknik untuk menyambung kayu dengan cara dipaku dan diperkuat dengan plat besi. Ada tiga cara teknik penyambungan, yaitu (a) sambungan sapatu disebut sambungan songgok (b) sambungan berbentuk "N" disebut sambungan runci (c) sambungan sulah yaitu sambungan berbentuk "L".

Apabila rangka rumah sudah berdiri di atas tiang-tiang dan sambungan kayu, begitu pula pemasangan atap sudah selesai, pengerjaan sudah tidak lagi secara gotong royong. Dilanjutkan dengan pemasangan tataban atau lantai, dinding atau bilik, pintu-pintu, jendela, dan kunci.

\section{k. N gabenteng}

Ngabenteng dilakukan setelah Imah Gede atau imah warga selesai dibangun. Proses ngabenteng adalah memasangkan batu-batu agar tanah tidak longsor. Ngabenteng adalah memasangkan batubatu pada tebing atau pinggir tebing, sedangkan ngabasisir adalah memasangkan batu-batu untuk jalan kecil (pedestrian) memasuki halaman rumah. Keahlian ngabenteng dan ngabasisir di Kasepuhan Sinar Resmi hanya dimiliki oleh tukang yang khusus, jarang orang yang mampu menjadi pekerja semacam ini.

\section{U pacara-upacara}


Beberapa salametan yang harus dilaksanakan oleh si empunya rumah terdiri atas beberapa tahap, yaitu:

\section{a. Salametan Samemehna (Selamatan Sebelum Mendirikan Rumah)}

Untuk memulai membuat pelataran rumah atau ngalelemah, si pemilik rumah mendatangi penghulu untuk membacakan doa dengan bahan yang diberkati oleh Abah. Sebelum pekerjaan dimulai penghulu membacakan doa dan membakar kemenyan bekal dari Abah serta menaburnaburkan panglay.

Begitu pula ketika akan memulai menebang kayu di hutan, biasanya si pemilik rumah mengadakan selamatan terlebih dahulu seperti menyediakan nasi ala kadarnya dan panghurip (bakakak ayam kampung) untuk didoakan oleh penghulu dan dimakan bersama-sama dengan orang-orang yang akan bekerja menebang pohon.

Sesajen yang disediakan oleh si pemilik rumah adalah: pangradinan, panglay, dan kemenyan. Berdoa dimulai pada waktu yang telah ditentukan, setelah itu kemenyan dibakar dan panglay disembur-semburkan ke setiap penjuru. Setelah proses doa selesai barulah pekerjaan dimulai.

\section{b. Salametan dina ngawangun (Sedang Mendirikan Rumah)}

Proses selamatan pada waktu membangun rumah dilakukan pada saat kerangka rumah telah selesai didirikan dan akan membangun kerangka atap yang disebut dengan nanjeurkeun. Penghulu disini berperan kembali, biasanya pemilik rumah menyediakan tumpeng dan menyembelih ayam, sedangkan sesajen yang disediakan adalah perwanten yaitu gula, kelapa, tebu, beras, garam, pecin, laja, jahe, sereh, bawang merah, bawang putih, pisang omas satu tandan nantinya dipergunakan untuk selamatan ketika akan memasuki rumah baru.Biasanya pisang yang digantungkan adalah pisang yang masih setengah mentah agar nanti ketika selesai pisang menjadi masak dan dapat dimakan. Semua perwanten ini digantungkan di atas tiang ander, sementara untuk Imah Gede perwanten lebih komplit lagi dengan pemasangan bendera merah putih.

\section{c. Salametan Saangeusna (Setelah Mendirikan Rumah)}

Upacara ngalebetanbumi biasanya dihadiri oleh Abah sebagai sesepuh kampung.Biasanya pelaksanaannya disesuaikan dengan perhitungan weton suami istri yang disatukan. Biasanya dilaksanakan pula ritual memasukkan barang dari pintu yang telah ditentukan sesuai dengan perhitungan.

Upacara ngalebetan bumi, yang pertama dibawa masuk ke dalam rumah adalah padaringan, karena padaringan merupakan benda yang dianggap pokok dalam setiap keluarga. Padaringan adalah wadah yang berisi beras. Beras adalah Nyi Pohaci yang harus dihormati.Apabila dalam upacara ngalebetan bumi tidak dilakukan maka akan terjadi malapetaka besar bagi pemilik rumah. Dengan demikian, menjadi hal yang sangat penting dan krusial sekali bahwapenempatan ruang goah dan Padaringan harus disesuaikan dengan weton atau hari kelahiran istri pemilik rumah.

Upacara ngalebetan Imah Gede lebih meriah lagi, karena abah sebagai sesepuh kampung menyediakan berbagai peralatan pertanian yang akan dibagikan kepada seluruh warga. Biasanya dalam upacara selamatan ini, peralatan pertanian menjadi bagian yang tidak boleh ditinggalkan dalam upacara ngalebetan Imah Gede.

\section{PEN UTUP}

Kasepuhan Sinar Resmi, merupakan sebuah komunitas adat dengan tradisi leluhurnya yang dinamis. Hal itu terbukti adanya keterbukaan terhadap dinamika dunia luar. Di samping kuatnya adat yang dipraktikkan dalam kehidupan sehari-hari, Kasepuhan Sinar Resmi, secara umum sangat menghormati lingkungan alam tempat mereka tinggal. Kearifan yang 
dimilikinya, mampu mempertahankan keharmonisan hubungan antara manusia dengan alamnya dan dalam kehidupan sosialnya.

Untuk menjaga keharmonisan tersebut, masyarakat Kasepuhan Sinar Resmi, memiliki kelenturan dalam mempertahankan tradisinya, serta menjalankan pola hidup yang harmonis dan sinergis antara tradisi, kepercayaan, adat dan pemerintah (nagara), yang dalam bahasa lokal disebut sebagai "sara, nagara jeung mokaha, tilu sapamulu, dua sakarupa, anu hiji eta keneh”. Praktik dalam menjalankan tradisi itu menciptakan sebuah keharmonisan yang tertuang dalam berbagai ritus. Ritus adalah sebagian dari kearifan yang menuntun mereka menjaga kelestarian lingkungan hidupnya.

Pembangunan sebuah rumah tak lepas dari ritus yang secara adat selalu dipatuhi dan dilaksanakan dengan benar, hal tersebut sangat erat kaitannya dengan sistem kepercayaan yang mereka anut. Kenapa hal itu dilaksanakan, karena mereka takut akan melanggar pamali. Demikian pula rumah dan pola perkampungan yang ada di Kasepuhan Sinar Resmi erat hubungannya dengan alam sekitar, sehingga rumah dapat dianalogikan sebagai 'mikro kosmos' atau bumi 'makro-kosmos' yang berarti alam semesta.

Dalam menentukan waktu, lokasi, dan tata cara untuk membangun tempat hunian baik perkampungan maupun rumah sebagai tempat tinggal (vernacular) maupun rumah adat) baru, masyarakat Kasepuhan Sinar Resmi sangat memerhatikan ritus yang dilakukannya. Hal tersebut akan memengaruhi kehidupan penghuninya secara baik atau buruk. Pemilihan waktu, tempat dan tatacara selalu mempertimbangkan keselarasan antara penghuni dengan kondisi tempatnya.

\section{DAFTAR SUMBER}

Adimiharja,K. O.S.Umsari, D. Sumardi \& E. Suryaatmana. 1986.
"Kesadaran Budaya Tentang Ruang Pada Masyarakat di Daerah Jawa Barat: Suatu studi mengenai proses adaptasi di Kampung Naga dan Kampung Tamiang. Depdik-bud, Direktorat Sejarah dan Nilai Tradisional, Proyek IDKD.

Ahimsa-Putra, Heddy Shri. 2001

Strukturalisme Levi-Straus: Mitos dan Karya Sastra. Galang Press, Yogyakarta.

Antar, Yori (ed) 2010.

"Pesan dari Wae Rebo" Kelahiran Kembali Arsitektur Nusantara Sebuah Pelajaran dari Masa Lalu untuk Masa Depan. Jakarta: Gramedia Pustaka Utama.

Harun, Ismet Belgawan, Nandang Rusnandar, Suparti Amir Salim, Irma Triastuti. 2011.

"Arsitektur Rumah dan Permukiman Tradisional di Jawa Barat Hasil Pengamatan dan Dokumentasi”. Bandung: Disparbud Provinsi Jawa Barat.

Rusnandar, Nandang. 2014

"Arsitektur Tradisional Di Kasepuhan Sinar Resmi Kabupaten Sukabumi Jawa Barat" dalam Patanjala Vol 6 No.3 September 2014. Hlm 413-430.

Salura, Purnama. 2008.

"Menelusuri Arsitektur Masyarakat Sunda”. Cipta Sastra Salura.

Subagya, Rachmat. 1981.

Agama Asli Indonesia. Jakarta: Yayasan Cipta Loka Caraka.

Tjahyono, Gunawan. 2010. Membangun Diri dan Mendiri Bangun Dalam Pembuatan Rumah Adat Di Desa Wae Rebo: Suatu Pengantar. Jakarta: Gramedia Pustaka Utama.

Tim Pra Penelitian Arsitektur Tradisional di Indonesia, 1982.

Data Tersusun Pengukuran Kampung Naga. Jurusan Arsitektur, Fakultas Teknik, Universitas Indonesia. 